\title{
MATURAÇÃO FISIOLÓGICA DE SEMENTES DE PIMENTA 'BODE VERMELHA'
}

\author{
VANESSA DAMASCENO GONÇALVES ${ }^{2 *}$, DANIELLE HELENA MÜLLER ${ }^{3}$, CARMEN LÚCIA FERREIRA FAVA $^{4}$, \\ ELISANGELA CLARETE CAMILI ${ }^{5}$
}

\begin{abstract}
RESUMO - A presente pesquisa objetivou avaliar a qualidade fisiológica de sementes de pimenta (Capsicum chinense Jacq.) var. Bode Vermelha obtidas de frutos em diferentes estádios de maturação. Os frutos de $C$. chinense foram separados em cinco estádios de maturação, baseando-se na coloração do pericarpo (frutos verdes estádio 1, frutos alaranjados - estádio 2, frutos vermelhos-claros - estádio 3, frutos vermelhos - estádio 4 e frutos vermelho-carmim - estádio 5). Para a avaliação da maturação e da qualidade fisiológica das sementes foram determinadas as características biométricas dos frutos e sementes, massa de mil sementes, teor de água das sementes, condutividade elétrica, teste padrão de germinação, tempo médio de germinação, porcentagem de plântulas normais, velocidade de formação de plântulas, além dos testes de envelhecimento acelerado, e comprimento de plântulas. Os caracteres comprimento, diâmetro, massa e número de sementes dos frutos e comprimento, largura, espessura e massa das sementes foram analisados por meio de parâmetros estimados utilizandose estatística descritiva. Para as demais variáveis foi utilizado delineamento experimental inteiramente casualizado. Os resultados foram submetidos à análise de variância e a comparação de médias pelo teste Scott-Knott, ao nível de 5\% de probabilidade. O estádio de maturação influencia na qualidade fisiológica das sementes de Capsicum chinense Jacq. var. Bode Vermelho, sendo as sementes oriundas de frutos de coloração vermelho (estádio 4) a vermelho-carmim (estádio 5) as que apresentaram os melhores desempenhos e, portanto, estão fisiologicamente maduras, sendo os mais indicados para obtenção das sementes.
\end{abstract}

Palavras-chave: Capsicum chinense. Germinabilidade. Vigor. Qualidade fisiológica.

\section{PHYSIOLOGICAL RIPENESS OF PEPPER 'BODE VERMELHA’ SEEDS}

\begin{abstract}
This research aimed to evaluate the physiological quality of pepper (Capsicum chinense Jacq.) var. Bode Vermelha seeds, obtained from fruits at different ripening stages. The fruits of $C$. Chinese were separated according to the ripening stages, based on pericarp color (green fruits - stage 1, orange fruits - stage 2 , light red fruits - stage 3, red fruits - stage 4, and carmine-red fruits - stage 5). To evaluate the ripeness and the physiological quality of the seeds were determined the biometric characteristics of the fruits and seeds, mass of thousand seeds, seeds water content, electrical conductivity, standard germinations test, speed of germination index, percentage of normal seedlings, speed of seedlings formation, accelerated aging, and seedling length. The characters length, diameter, weight, and number of seeds of the fruits and length, width, thickness, and mass of the seeds were analyzed by the estimated parameters using descriptive statistics. For the other variables was used the completely randomized design. The results were submitted to variance analysis and comparison of means by the Scott-Knott test at $5 \%$ probability. The ripeness stage affects the physiological quality of C. chinense Jacq. var. Bode Red seeds, being the seeds from red (stage 4) to carmine-red (stage 5) fruits those with the best performance thus, they are physiologically ripe, being the most indicated to seeds obtaining.
\end{abstract}

Keywords: Capsicum chinense. Germination. Vigor. Physiological quality.

\footnotetext{
*Autor para correspondência

${ }^{1}$ Recebido para publicação em 22/10/2014; aceito em 28/04/2015.

${ }^{2}$ Mestranda em Agricultura Tropical pela Universidade Federal de Mato Grosso (UFMT), Av. Fernando Corrêa da Costa, $\mathrm{n}^{\circ} 2367$, Bairro Boa Esperança, Campus Cuiabá (MT), Brasil; vanessa-d-goncalves@hotmail.com.

${ }^{3}$ Doutoranda em Agricultura Tropical pela UFMT, Campus Cuiabá (MT), Brasil.

${ }^{4}$ Doutora em Agricultura Tropical, Rua São Joaquim, 1090, Bairro Centro Sul, 78.020-150, Cuiabá (MT), Brasil

${ }^{5}$ Professora do Departamento de Fitotecnia e Fitossanidade, UFMT, Campus Cuiabá (MT), Brasil.
} 


\section{INTRODUÇÃO}

As pimentas (Capsicum sp.), pertencentes à família Solanaceae, constituem um importante segmento do setor de hortaliças, tanto para a agricultura quanto para a indústria alimentícia. Elas são especiais para a produção de condimentos devido às características de coloração dos frutos e princípios ativos, os quais lhes conferem aroma e sabor (MOREIRA et al., 2006).

As pimenteiras são plantas que possuem crescimento indeterminado e florescimento e frutificação contínuos (VIDIGAL et al., 2009), o que resulta em completa desuniformidade de desenvolvimento de frutos e sementes. Assim, são encontrados em uma mesma planta frutos em diversos estádios de maturação, o que dificulta a determinação da época de maturidade fisiológica das sementes e, consequentemente, o momento ideal de colheita dos frutos para obtenção de sementes com alta qualidade fisiológica (CARVALHO; NAKAGAWA, 2012; VIDIGAL et al., 2009), demonstrando que pesquisas relacionadas à maturidade das sementes, com base na coloração dos frutos, são imprescindíveis para a definição do momento ideal de colheita, a fim de que a máxima qualidade seja alcançada em campo (ABUD et al., 2013).

A maturação da semente é considerada resultado de todas as alterações morfológicas, físicas e fisiológicas, como o aumento do tamanho e as variações no teor de água, no vigor e no acúmulo de matéria seca, dentre outras. Ela tem início com a fertilização e se estende até a maturidade fisiológica
(MARCOS FILHO, 2005) e em espécies de frutos carnosos, como a pimenta, a maturidade fisiológica coincide com a alteração da coloração do exocarpo (ABUD et al., 2013).

$\mathrm{O}$ vigor das sementes compreende um conjunto de características que determinam seu potencial fisiológico, o qual é influenciado pelas condições de ambiente, genótipo e manejo durante as etapas de pré e pós-colheita (MARCOS FILHO et al., 1987). Pereira (2014) verificou que o repouso pós-colheita dos frutos de pimenta, variedade Dedo-de-Moça, por dez dias, melhora o potencial fisiológico das sementes.

Sendo assim, o objetivo deste trabalho foi avaliar a qualidade fisiológica de sementes de Capsicum chinense Jacq., var. Bode Vermelho, em diferentes estádios de maturação com base na coloração do exocarpo dos frutos.

\section{MATERIAL E MÉTODOS}

Os frutos de C. chinense Jacq., var. Bode Vermelho, foram adquiridos no mercado varejista "Antônio Moisés Nadaf" - Mercado do Porto, em Cuiabá (MT). Após a aquisição dos frutos estes foram levados para o Laboratório de Pesquisa em Sementes da Universidade Federal de Mato Grosso (UFMT), onde procedeu-se a seleção visual do estádio de maturação, baseado na coloração dos frutos, separando-os em cinco estádios: frutos verdes (estádio 1); frutos alaranjados (estádio 2); frutos vermelhos-claros (estádio 3); frutos vermelhos (estádio 4); e frutos vermelho-carmim (estádio 5) (Figura 1).

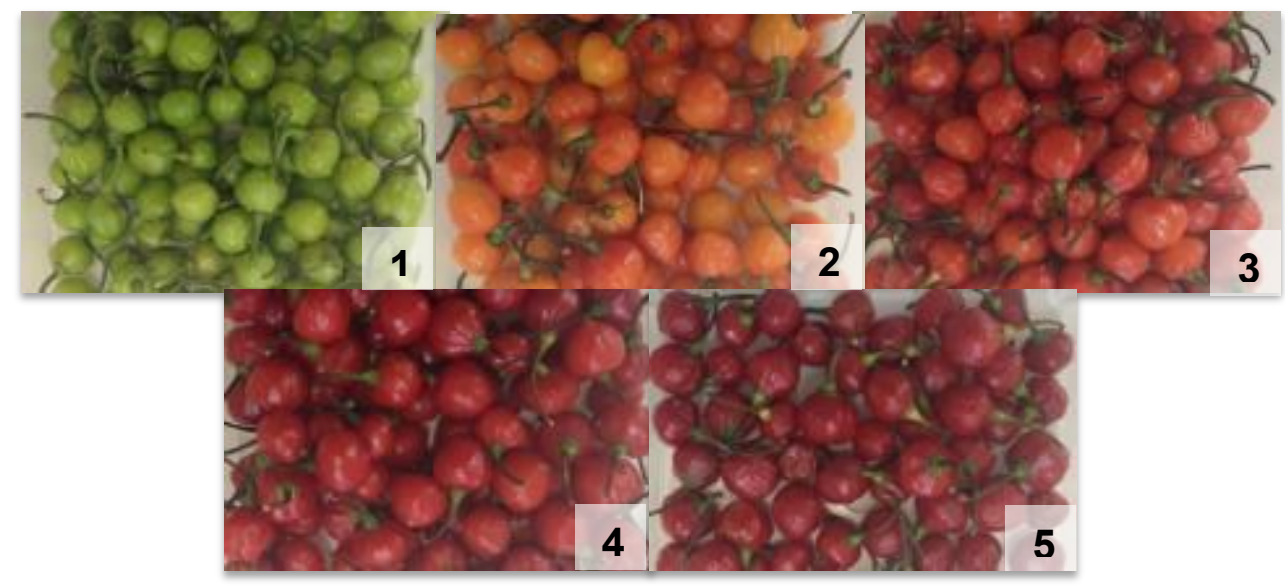

Figura 1. Frutos de pimenta (Capsicum chinense Jacq.), var. Bode Vermelho, obtidos de acordo com a coloração do pericarpo. Estádio 1 (frutos verdes), estádio 2 (frutos alaranjados), estádio 3 (frutos vermelhos-claros), estádio 4 (frutos vermelhos) e estádio 5 (frutos vermelho-carmim).

Após a determinação dos estádios de maturação (EM) dos frutos foram realizados a caracterização biométrica e os testes para avaliação da qualidade fisiológica das sementes:
Caracterização biométrica - de acordo com a metodologia utilizada por Fava (2014), medindo-se 30 frutos e 30 sementes recém-extraídas, tomados aleatoriamente de cada estádio de maturação. O comprimento e o diâmetro dos frutos e o comprimento (no 
sentido longitudinal), a largura (no sentido transversal) e a espessura das sementes foram medidos com paquímetro digital com precisão de $0,01 \mathrm{~mm}$. $\mathrm{O}$ comprimento dos frutos, sem o pedúnculo, foi medido da base até o ápice, e o diâmetro dos frutos e as dimensões das sementes medidos na linha mediana dos mesmos. Os valores de massa da matéria fresca dos frutos e sementes foram obtidos mediante pesagens em balança analítica com precisão de 0,0001 g. E fora determinado ainda a quantidade de sementes por fruto (número de sementes).

Após a extração manual das sementes com auxílio de um bisturi para abertura dos frutos determinou-se a massa de mil sementes e o teor de água, utilizando o método da estufa a $105 \pm 3{ }^{\circ} \mathrm{C}$ por 24 horas para cada estádio de maturação (BRASIL, 2009).

Condutividade elétrica - realizado com quatro repetições de 50 sementes de cada estádio de maturação e pesadas com precisão de quatro casas decimais. As sementes foram colocadas em copos plásticos, onde foram adicionados $25 \mathrm{~mL}$ de água destilada. Os copos contendo as sementes e a água destilada permaneceram em câmara de germinação do tipo Biochemical Oxigen Demand (B.O.D.) a $25{ }^{\circ} \mathrm{C}$ durante 24 horas (VIDIGAL et al., 2008). Decorrido o tempo de incubação procedeu-se as leituras de condutividade através de condutivímetro e os resultados expressos em $\mu \mathrm{S} \mathrm{cm}^{-1} \mathrm{~g}^{-1}$ de semente.

Porcentagem de germinação - conduzido com quatro repetições de 50 sementes para cada estádio de maturação. As sementes foram semeadas em caixas plásticas transparentes do tipo "gerbox" $(11$ x 11 x 3 $\mathrm{cm})$ sobre duas folhas de papel mata-borrão umedecida com água destilada até a saturação. As caixas foram envolvidas com filme de plástico, tampadas e mantidas em câmara de germinação do tipo B.O.D. sob a temperatura alternada $20-30{ }^{\circ} \mathrm{C}$, em fotoperíodo de 12 horas (BRASIL, 2009), com leituras diárias até 14 dias após a semeadura para determinação do tempo médio de germinação (TMG) e da velocidade de formação de plântulas (VFP). As sementes foram consideradas germinadas quando ocorreu a protrusão da raiz primária com $2 \mathrm{~mm}$ de comprimento e considerou-se como plântula normal as que apresentaram as estruturas de parte aérea e raiz desenvolvidas.

Teste de envelhecimento acelerado (EA) - adotouse o método de caixas de plástico $(11 \times 11 \times 3 \mathrm{~cm})$ com tela suspensa (AOSA, 2002). Uma amostra de aproximadamente 200 sementes de cada estádio foi acondicionada em camada única sobre a tela em caixa de plástico contendo $40 \mathrm{~mL}$ de água destilada deionizada, as quais foram mantidas em câmara de germinação tipo B.O.D. a $41{ }^{\circ} \mathrm{C}$ por 72 horas (TORRES, 2005). Pelo fato das sementes serem pequenas e não preencherem toda a tela fora utilizado sementes de soja para completar o espaço vazio que restou sobre a tela. Decorrido o período de incubação quatro subamostras de 50 sementes de cada estádio foram colocadas para germinar seguindo o método descrito anteriormente para o teste de germinação, no qual foi avaliado o número de sementes germinadas, o número de plântulas normais e anormais.

Comprimento de plântulas - foram utilizadas quatro repetições com 10 sementes de cada estádio. As sementes foram distribuídas sobre papel toalha tipo germitest e umedecidas com quantidade de água equivalente a 2,5 vezes a massa do substrato seco. Os rolos foram acondicionados em sacos plásticos posicionados verticalmente em câmara de germinação tipo B.O.D. em temperaturas alternadas de 20 $30{ }^{\circ} \mathrm{C}$ por 14 dias, no escuro, conforme Nakagawa (1999). Decorrido os 14 dias mensurou-se o comprimento da raiz e da parte área utilizando régua milimétrica.

As variáveis comprimento, diâmetro, massa e número de sementes dos frutos e comprimento, largura, espessura e massa das sementes foram analisadas por meio de parâmetros estimados utilizando-se estatística descritiva. Para as demais variáveis foi utilizado delineamento experimental inteiramente casualizado, com cinco tratamentos e quatro repetições. Os tratamentos foram constituídos pelos estádios de maturação $1,2,3,4$ e 5, cada estádio com quatro repetições de 50 sementes. Os resultados foram submetidos à análise de variância e à comparação de médias pelo teste Scott-Knott, ao nível de 5\% de probabilidade, utilizando o programa estatístico Assistat (SILVA, 2014).

\section{RESULTADOS E DISCUSSÃO}

As diferenças biométricas de frutos e sementes de $C$. chinense, var. Bode Vermelho, nos cinco estádios de maturação estão na Tabela 1. A menor média de massa dos frutos e a maior média de número de sementes por fruto ocorreu no Estádio 1. Segundo Freitas et al. (2009), alguns fatores, como o número de óvulos produzidos, quantidade e qualidade do pólen transferido, quantidade de nutrientes e fotoassimilados disponíveis para os frutos e sementes (limitação de recursos), além dos ataques de herbívoros, predadores e doenças, podem explicar as diferenças no número de sementes por fruto. Porém, vale ressaltar que nesse estudo não foram observados sinais de ataques e muito menos desenvolvimento de patógenos nos frutos. 
Tabela 1. Parâmetros biométricos de frutos e sementes de pimenta (Capsicum chinense Jacq.), var. Bode Vermelho, em função dos estádios de maturação dos frutos.

\begin{tabular}{|c|c|c|c|c|c|c|c|c|}
\hline \multirow{2}{*}{ Características } & \multirow{2}{*}{ Estádios } & \multicolumn{7}{|c|}{ Frutos } \\
\hline & & Min. & Max. & $\bar{x}$ & DP & CV (\%) & $\mathrm{S}$ & $\mathrm{K}$ \\
\hline \multirow{6}{*}{ Comprimento } & 1 & 10,4 & 16,5 & 13,3 & 1,3 & 10,1 & $-0,3$ & 0,5 \\
\hline & 2 & 10,1 & 17,5 & 13,9 & 1,5 & 10,7 & $-0,5$ & 1,6 \\
\hline & 2 & 11 & 160 & 125 & 14 & 102 & $00 ?$ & ? \\
\hline & & & & (1) & $1, T$ & J & 0,02 & 0,2 \\
\hline & 4 & 10,5 & 17,7 & 14,0 & 1,7 & 12,3 & $-0,2$ & $-0,4$ \\
\hline & 5 & 11,1 & 17,3 & 14,1 & 1,4 & 9,6 & 0,3 & 0,5 \\
\hline \multirow{5}{*}{ Diâmetro (mm) } & 1 & 9,0 & 14,9 & 13,1 & 1,4 & 10,5 & $-1,3$ & 1,8 \\
\hline & 2 & 11,8 & 15,4 & 13,5 & 1,0 & 7,2 & $-0,006$ & $-1,1$ \\
\hline & 3 & 12,2 & 16,8 & 13,9 & 1,1 & 7,8 & 0,7 & 0,2 \\
\hline & 4 & 12,0 & 15,7 & 14,2 & 1,0 & 6,8 & $-0,2$ & $-0,5$ \\
\hline & 5 & 11,6 & 16,0 & 13,8 & 1,1 & 7,8 & 0,02 & $-0,02$ \\
\hline \multirow{5}{*}{ Massa (g) } & 1 & 0,4 & 1,3 & 0,9 & 0,2 & 22,3 & $-0,8$ & 1,0 \\
\hline & 2 & 0,7 & 1,4 & 1,0 & 0,2 & 20,7 & 0,3 & $-1,1$ \\
\hline & 3 & 0,7 & 1,5 & 1,0 & 0,2 & 20,6 & 0,4 & $-0,7$ \\
\hline & 4 & 0,7 & 1,4 & 1,1 & 0,2 & 18,8 & $-0,4$ & $-0,9$ \\
\hline & 5 & 0,7 & 1,5 & 1,1 & 0,2 & 22,4 & 0,4 & $-0,8$ \\
\hline \multirow{5}{*}{$\mathrm{N}^{\circ}$ de sementes } & 1 & 24 & 56 & 38 & 8,0 & 20,8 & 0,3 & $-0,4$ \\
\hline & 2 & 16 & 50 & 32 & 7,8 & 24,0 & 0,1 & 0,01 \\
\hline & 3 & 15 & 52 & 32 & 9,5 & 30,5 & 0,1 & $-1,0$ \\
\hline & 4 & 17 & 53 & 35 & 10,1 & 29,2 & 0,1 & $-1,1$ \\
\hline & 5 & 16 & 55 & 34 & 8,8 & 25,9 & 0,4 & 0,5 \\
\hline
\end{tabular}

Min. = mínimo, Max. = máximo, ${ }^{\bar{x}}=$ média, $\mathrm{DP}=$ desvio padrão, $\mathrm{S}=$ assimetria, e $\mathrm{K}=$ curtose.

Estádio 1 - frutos verdes, estádio 2 - frutos alaranjados, estádio 3 - frutos vermelhos-claros, estádio 4 - frutos vermelhos, e estádio 5 - frutos vermelho-carmim. 
Tabela 1. Continuação.

\begin{tabular}{|c|c|c|c|c|c|c|c|c|}
\hline \multirow{2}{*}{ Características } & \multirow{2}{*}{ Estádios } & \multicolumn{7}{|c|}{ Sementes } \\
\hline & & Min. & Max. & $\bar{x}$ & DP & CV (\%) & $\mathrm{S}$ & $\mathrm{K}$ \\
\hline \multirow{5}{*}{ Comprimento (mm) } & 1 & 2,4 & 4,3 & 3,5 & 0,5 & 13,1 & $-0,3$ & $-0,3$ \\
\hline & 2 & 2,6 & 3,8 & 3,3 & 0,3 & 9,7 & $-0,3$ & $-0,7$ \\
\hline & 3 & 2,5 & 4,2 & 3,6 & 0,4 & 10,6 & $-0,6$ & $-0,7$ \\
\hline & 4 & 2,6 & 4,2 & 3,7 & 0,4 & 10,8 & $-1,3$ & 1,6 \\
\hline & 5 & 2,7 & 4,3 & 3,7 & 0,4 & 9,8 & $-0,6$ & 0,2 \\
\hline \multirow{5}{*}{ Largura $(\mathrm{mm})$} & 1 & 2,1 & 3,7 & 3,0 & 0,4 & 12,2 & $-0,6$ & 0,9 \\
\hline & 2 & 2,5 & 3,8 & 3,1 & 0,3 & 8,7 & $-0,03$ & 0,7 \\
\hline & 3 & 2,7 & 3,9 & 3,2 & 0,3 & 10,4 & 0,4 & $-0,7$ \\
\hline & 4 & 2,5 & 3,8 & 3,2 & 0,3 & 11,1 & $-0,2$ & $-0,7$ \\
\hline & 5 & 2,7 & 3,6 & 3,2 & 0,2 & 7,1 & $-0,2$ & $-0,3$ \\
\hline \multirow{5}{*}{ Espessura (mm) } & 1 & 0,2 & 0,9 & 0,4 & 0,2 & 37,0 & 1,1 & 0,9 \\
\hline & 2 & 0,5 & 1,1 & 0,7 & 0,1 & 19,9 & 0,7 & 0,1 \\
\hline & 3 & 0,5 & 1,1 & 0,7 & 0,1 & 21,1 & 1,0 & 1,2 \\
\hline & 4 & 0,4 & 1,1 & 0,7 & 0,1 & 20,7 & 0,6 & 1,3 \\
\hline & 5 & 0,5 & 1,0 & 0,7 & 0,1 & 16,9 & 1,1 & 1,3 \\
\hline \multirow{5}{*}{ Massa (g) } & 1 & 0,001 & 0,004 & 0,002 & 0,001 & 36,7 & 0,2 & $-0,5$ \\
\hline & 2 & 0,002 & 0,004 & 0,003 & 0,001 & 19,6 & $-0,9$ & 0,3 \\
\hline & 3 & 0,001 & 0,005 & 0,004 & 0,001 & 28,4 & $-0,7$ & $-0,2$ \\
\hline & 4 & 0,001 & 0,005 & 0,003 & 0,001 & 38,7 & $-0,8$ & $-0,5$ \\
\hline & 5 & 0,004 & 0,005 & 0,004 & 0,001 & 12,8 & 0,1 & $-1,0$ \\
\hline
\end{tabular}

Min. = mínimo, Max. = máximo, ${ }^{\bar{x}}=$ média, $\mathrm{DP}=$ desvio padrão, $\mathrm{S}=$ assimetria, e $\mathrm{K}=$ curtose.

Estádio 1 - frutos verdes, estádio 2 - frutos alaranjados, estádio 3 - frutos vermelhos-claros, estádio 4 - frutos vermelhos, e estádio 5 - frutos vermelho-carmim. 
A variação nos valores dos dados biométricos pode ocorrer devido as alterações fisiológicas que provocam acréscimos nos valores das variáveis biométricas com o decorrer da maturação dos frutos (ABUD, 2013).

$\mathrm{Na}$ avaliação das características das sementes observou-se que o estádio 1 teve a menor média de espessura, enquanto que a menor média no comprimento foi obtida no estádio 2 (Tabela 1), da mesma forma que nos frutos. A massa das sementes aumentou com o decorrer da maturação dos frutos. Isso ocorre devido ao acúmulo de metabólitos translocados da planta para as sementes durante a maturação
(BEWLEY et al., 2013), podendo-se inferir que isso refletiu na modificação das características físicas das mesmas.

A massa de mil sementes também aumentou de acordo com o avanço do estádio de maturação dos frutos (Tabela 2), como esperado, levando em consideração que a média da massa de cada semente aumentou com o grau de maturação. As sementes dos estádios 4 e 5 estavam mais maduras e bem formadas e apresentavam maior tamanho, enquanto que as sementes do estádio 1 ainda estavam pequenas e mal formadas.

Tabela 2. Peso de mil sementes e teor de água das sementes de pimenta (Capsicum chinense Jacq.), var. Bode Vermelho, em função dos estádios de maturação dos frutos.

\begin{tabular}{|c|c|c|c|}
\hline \multirow{2}{*}{ Estádio } & \multicolumn{3}{|c|}{ Peso de mil sementes (g) } \\
\hline & $\mathrm{g}$ & Desvio padrão & $\mathrm{CV}(\%)$ \\
\hline 1 & 1,2 & 0,011 & 8,5 \\
\hline 2 & 2,9 & 0,007 & 2,4 \\
\hline 3 & 3,5 & 0,010 & 3,0 \\
\hline 4 & 3,8 & 0,012 & 3,2 \\
\hline 5 & 3,9 & 0,010 & 2,7 \\
\hline \multirow{2}{*}{ Estádio } & \multicolumn{3}{|c|}{ Teor de água (\%) } \\
\hline & $\%$ & Desvio padrấo & $\mathrm{CV}(\%)$ \\
\hline 1 & 76,3 & 0,604 & 0,8 \\
\hline 2 & 46,2 & 1,302 & 2,8 \\
\hline 3 & 45,1 & 1,400 & 3,1 \\
\hline 4 & 32,4 & 0,337 & 1,0 \\
\hline 5 & 43,2 & 1,350 & 3,1 \\
\hline
\end{tabular}

Estádio 1- frutos verdes, estádio 2 - frutos alaranjados, estádio 3 - frutos vermelhos-claros, estádio 4 - frutos vermelhos, e estádio 5 - frutos vermelho-carmim.

O teor de água das sementes decresceu com o avanço da maturação dos frutos, de maneira mais expressiva do estádio 1 para o estádio 2 . O estádio 5 teve pequeno aumento no teor de água em relação ao estádio 4 (Tabela 2).

A medida que as sementes amadurecem fisiologicamente acumulam matéria seca, consequentemente a massa de mil sementes aumenta e simultaneamente ocorre perda natural de água das sementes. Todo este processo está diretamente relacionado com o aumento do potencial fisiológico das sementes, considerando que o vigor das sementes aumenta com o decorrer da maturação, atingindo o máximo em momento próximo ou coincidente com o máximo acúmulo de reservas (MARCOS FILHO, 2005).

Ao estudar a cultura da abobrinha, cultivar Menina Brasileira, Marrocos et al. (2011) também observaram redução no teor de água das sementes, avaliando frutos com idade a partir de 20 dias após a antese, com estabilização a partir dos 50 dias e, segundo esses autores, elevado teor de água inicial nas sementes justificado pela necessidade destas sintetizar e metabolizar materiais de reserva que ocorrem em meio aquoso. De acordo com Bewley et al. (2013), o alto teor de água no início da maturação é necessário tanto para a expansão celular quanto para a translocação de metabólitos da planta para as se- mentes, além de ser fundamental para o posterior acúmulo das reservas. Embora seja bastante utilizado, o teor de água das sementes não é um indicador adequado do ponto de maturidade fisiológica por sofrer influências ambientais e genéticas (WELBAUM; BRADFORD, 1988), fato que possivelmente será identificado neste trabalho, com estudo da percentagem de germinação das sementes.

Também foi observado por Pereira et al. (2014), Abud et al. (2013) e Vidgal et al. (2011) que o avanço dos estádios de maturação promoveu redução no teor de água das sementes das pimentas dedode-moça, malagueta e biquinho e 'Amarela comprida', respectivamente.

Os dados do teste de condutividade elétrica (Tabela 3) apontam redução dos valores com a maturação dos frutos, indicando aumento no vigor das sementes. O mesmo foi observado por Pereira et al. (2014) em pimenta dedo-de-moça, onde os resultados indicam que no início as sementes possuem menor potencial fisiológico, liberando maior quantidade de lixiviado devido a menor estruturação e seletividade das membranas, e com o avanço da maturação ocorre uma estruturação adequada das membranas celulares reduzindo, desta forma, a lixiviação de solutos. Segundo Martins et al. (2012), existe a possibilidade do sistema de proteção de membranas celula- 
res ser ineficiente nos estágios iniciais do desenvolvimento, quando as membranas ainda não estão bem constituídas. Assim, os processos de deterioração das membranas iniciam-se nos estágios mais avançados do desenvolvimento, quando elas estão mal estruturadas.

Tabela 3. Condutividade elétrica de sementes de pimenta (Capsicum chinense Jacq.), var. Bode Vermelho, em função dos estádios de maturação dos frutos.

\begin{tabular}{cc}
\hline Estádio & Condutividade elétrica $\left(\mu \mathrm{S} \mathrm{cm}^{-1} \mathrm{~g}^{-1}\right)$ \\
\hline 1 & $2321,76^{*} \mathrm{a}$ \\
2 & $645,11 \quad \mathrm{~b}$ \\
3 & $534,40 \quad \mathrm{c}$ \\
4 & $457,60 \mathrm{c}$ \\
5 & $454,17 \quad \mathrm{c}$ \\
\hline CV (\%) & 6,36 \\
\hline
\end{tabular}

*Médias seguidas pela mesma letra não diferem estatisticamente entre si ao nível de $5 \%$ de probabilidade pelo Teste de Scott-Knott.

CV: Coeficiente de variação.

Estádio 1- frutos verdes, estádio 2 - frutos alaranjados, estádio 3 - frutos vermelhos-claros, estádio 4 - frutos vermelhos, e estádio 5 - frutos vermelho-carmim.

O avanço da maturidade das sementes não influenciou a porcentagem de plântulas normais, pois as sementes dos estádios 4 e 5 apresentaram a mesma porcentagem de plântulas normais que as do estádio 2 (Tabela 4), com exceção do estádio 1 , em que as sementes se apresentaram visualmente imaturas. Este fato pode estar relacionado ao menor teor água observado nas sementes a partir do estádio 2 de maturação (Tabela 2), denotando o máximo de acúmulo de fotossintatos nas sementes. Queiroz et al.
(2011) explicam que quando as sementes atingem a maturidade fisiológica elas são capazes de germinar e gerar plântulas normais, apresentando todos os aparatos químicos e fisiológicos necessários para tal. Os autores supracitados também afirmam que a ocorrência de dormência associada à imaturidade fisiológica das sementes fundamenta a germinação e o vigor reduzidos das sementes. Segundo Queiroz et al. (2011), sementes recém-colhidas de espécies do gênero Capsicum podem apresentar dormência.

Tabela 4. Germinação (G), plântulas normais (PN), tempo médio de germinação (TMG) e velocidade de formação de plântulas (VFP) de pimenta (Capsicum chinense Jacq.), var. Bode Vermelho, em função dos estádios de maturação dos frutos.

\begin{tabular}{|c|c|c|c|c|}
\hline Estádio & G (\%) & PN (\%) & TMG (dias) & VFP (dias) \\
\hline 1 & $5^{*} \mathrm{c}$ & $1 \mathrm{~b}$ & $8,3 \mathrm{a}$ & $14,0 \mathrm{a}$ \\
\hline 2 & $74 \mathrm{~b}$ & $37 \mathrm{a}$ & $7,8 \mathrm{~b}$ & $11,8 \mathrm{~b}$ \\
\hline 3 & $74 \mathrm{~b}$ & $17 \mathrm{~b}$ & $7,4 \mathrm{c}$ & $12,3 \mathrm{~b}$ \\
\hline 4 & $96 \mathrm{a}$ & $30 a$ & $7,0 \mathrm{c}$ & $11,0 \mathrm{c}$ \\
\hline 5 & $89 \mathrm{a}$ & $40 \mathrm{a}$ & $5,8 \mathrm{~d}$ & $10,2 \mathrm{c}$ \\
\hline CV (\%) & 12,55 & 62,83 & 4,08 & 5,07 \\
\hline
\end{tabular}

*Médias seguidas pela mesma letra na coluna não diferem estatisticamente entre si ao nível de $5 \%$ de probabilidade pelo Teste de Scott-Knott.

$\mathrm{CV}$ : Coeficiente de variação.

Estádio 1- frutos verdes, estádio 2 - frutos alaranjados, estádio 3 - frutos vermelhos-claros, estádio 4 - frutos vermelhos, e estádio 5 - frutos vermelho-carmim. 
Os resultados de germinação das sementes deste trabalho são diferentes dos relatados por Belletti e Quagliotti (1989), os quais observaram que sementes de espécies do gênero Capsicum podem requerer até 45 dias para que germinem satisfatoriamente. Porém, muitas variáveis podem interferir neste fator como, por exemplos, a cultivar, as condições de cultivo e os fatores climáticos.

Em relação ao tempo médio de germinação (TMG) e a velocidade de formação das plântulas (VFP), percebe-se redução na medida em que ocorre progresso da maturação, o que torna-se um fator importante, inferindo que quanto mais rápido for $\mathrm{o}$ crescimento menor será a suscetibilidade das plântulas à intempéries.

Também foi observado por Ricci et al. (2013) relação direta entre a idade e maturação do fruto com a velocidade de germinação das sementes de pimenta jalapenho. $\mathrm{O}$ maior vigor e qualidade fisiológica das sementes colhidas de frutos com maior idade explicam essa relação, segundo Nakada et al. (2011). Esses trabalhos esclarecem o motivo das sementes extraídas dos frutos do estádio 5 apresentarem maior porcentagem de germinação em menor tempo.

A maturidade influencia na germinação das sementes de pimentas malagueta e biquinho até os 71 e 79 dias após a antese (DAA), respectivamente, no qual verificaram que a porcentagem de germinação aumentou. Relatam ainda que após esse período houve redução na germinação (ABUD et al., 2013).

Mesmo após o processo de envelhecimento acelerado verificou-se a ocorrência de maior número de plântulas normais nos estádios 3 e 5 . A alta temperatura do envelhecimento acelerado pode ter eliminado patógenos presentes externamente nas sementes, e como estas eram bastante vigorosas conseguiram se desenvolver melhor que no teste padrão de germinação. Em contrapartida, o teste de envelhecimento acelerado reduziu a porcentagem de germinação e somente os estádios 4 e 5 mantiveram o percentual de germinação próximo ao obtido no teste padrão (Tabela 5). No estudo de Abud et al. (2013) feito com pimentas malagueta e biquinho os autores observaram que no estágio de maturação dos 55 a 71 DAA (dias após a antese), para a pimenta malagueta, e 55 a 78 DAA, para a pimenta biquinho, houve incremento no vigor. Após esse período o mesmo diminuiu com o envelhecimento acelerado das sementes. Queiroz et al. (2011) constataram que o vigor após o envelhecimento acelerado, em sementes de pimenta habanero, foi maior para as sementes colhidas aos 67 DAA, e que as que foram colhidas aos 50 e 60 DAA apresentaram o vigor praticamente nulo. Já no experimento com pimenta 'Amarela comprida', feito por Vidigal et al. (2011), a porcentagem de germinação se manteve quase constante dos 55 até os 75 DAA.

Tabela 5. Porcentagens de plântulas normais (PN), anormais (PA), sementes germinadas (G) após o teste de envelhecimento acelerado das sementes de pimenta (Capsicum chinense Jacq.), var. Bode Vermelho, em função dos estádios de maturação dos frutos.

\begin{tabular}{cccc}
\hline Estádio & PN (\%) & PA (\%) & G (\%) \\
\hline 1 & $00,0^{*} \mathrm{c}$ & $00,0 \mathrm{a}$ & $00,0 \mathrm{~d}$ \\
2 & $50 \mathrm{~b}$ & $15 \mathrm{a}$ & $79 \mathrm{c}$ \\
3 & $75 \mathrm{a}$ & $5 \mathrm{a}$ & $89 \mathrm{a}$ \\
4 & $66 \mathrm{~b}$ & $23 \mathrm{a}$ & $88 \mathrm{a}$ \\
\hline CV $(\%)$ & $87 \mathrm{a}$ & $1 \mathrm{a}$ & 4,45
\end{tabular}

*Médias seguidas pela mesma letra na coluna não diferem estatisticamente entre si ao nível de 5\% de probabilidade pelo Teste de Scott-Knott.

CV: Coeficiente de variação.

Estádio 1- frutos verdes, estádio 2 - frutos alaranjados, estádio 3 - frutos vermelhos-claros, estádio 4 - frutos vermelhos, e estádio 5 - frutos vermelho-carmim.

No teste para avaliar o comprimento de raiz e parte aérea de plântulas as sementes do estádio 1 não germinaram (Tabela 6). Observou-se que nos estádios com sementes mais maduras as plântulas apresentaram maior comprimento de raiz, isso até o estádio 4 , pois no estádio 5 houve pequeno decréscimo nesse comprimento. Negreiros et al. (2006) sugerem que a completa maturação fisiológica das sementes favorece o crescimento das plântulas. Carvalho e Nakagawa (2012) afirmam que as sementes que não estão completamente maduras podem até germinar, porém não resultarão em plântulas vigorosas como as provindas de sementes maduras. 
Tabela 6. Comprimento de raiz (CR) e parte aérea (CP) das plântulas de pimenta (Capsicum chinense Jacq.), var. Bode Vermelho, em função dos estádios de maturação dos frutos.

\begin{tabular}{ccc}
\hline Estádio & CR $(\mathrm{cm})$ & $\mathrm{CP}(\mathrm{cm})$ \\
\hline 1 & $0,00^{*} \mathrm{~d}$ & $0,00 \mathrm{~b}$ \\
2 & $1,79 \mathrm{c}$ & $1,49 \mathrm{a}$ \\
3 & $2,41 \mathrm{c}$ & $1,36 \mathrm{a}$ \\
4 & $3,77 \mathrm{a}$ & $1,73 \mathrm{a}$ \\
5 & $2,98 \mathrm{~b}$ & $1,44 \mathrm{a}$ \\
\hline $\mathrm{CV}(\%)$ & 21,72 & 42,40
\end{tabular}

*Médias seguidas pela mesma letra na coluna não diferem estatisticamente entre si ao nível de $5 \%$ de probabilidade pelo Teste de Scott-Knott.

CV: Coeficiente de variação.

Estádio 1- frutos verdes, estádio 2 - frutos alaranjados, estádio 3 - frutos vermelhos-claros, estádio 4 - frutos vermelhos, e estádio 5 - frutos vermelho-carmim.

\section{CONCLUSÃO}

O estádio de maturação do fruto influencia na qualidade fisiológica das sementes de Capsicum chinense, var. Bode Vermelho, sendo os frutos de coloração vermelho (estádio 4) a vermelho-carmim (estádio 5) os mais indicados para obtenção das sementes.

\section{AGRADECIMENTOS}

À Coordenação de Aperfeiçoamento Pessoal de Ensino Superior (Capes) pela concessão das bolsas de estudo.

\section{REFERÊNCIAS}

ABUD, H. F. et al. Qualidade fisiológica de sementes das pimentas malagueta e biquinho durante a ontogênese. Pesquisa Agropecuária Brasileira, Brasília, v. 48, n. 12, p. 1546-1554, 2013.

\section{ASSOCIATION OF OFFICIAL SEED} ANALYSTS. Seed vigor testing handbook. Lincoln: AOSA, 2002. 105 p. Contribution, 32.

BELletTI, P.; QUAGLiOTTI, L. Problems of seed production and storage of pepper. In: INTERNATIONAL SYMPOSIUM ON INTEGRATED MANAGEMENT PRACTICES, 1., 1989, Shanhua. Anais... Shanhua: AVRDC, 1989. p. 28-41.

BEWLEY, J. D. et al. Seeds: physiology of development, germination and dormancy. 3rd ed. New York: Springer, 2013. $392 \mathrm{p}$.
BHERING, M. C. et al. Teste de envelhecimento acelerado em sementes de pimenta. Revista Brasileira de Sementes, Pelotas, v. 28, n. 3, p. 64-71, 2006.

BRASIL. Ministério da Agricultura, Pecuária e Abastecimento. Regras para análise de Sementes. Secretaria de Defesa Agropecuária. Brasília: MAPA/ ACS5, 2009. 395 p.

CARVAlHO, N. M.; NAKAGAWA, J. Sementes: ciência, tecnologia e produção. 5. ed. Jaboticabal: Funep, 2012. 590 p.

FAVA, C. L. F. Aspectos morfológicos e fisiológicos de diásporos e plântulas de 24 espécies do Cerrado. 2014. 130 f. Tese (Doutorado em Agricultura Tropical) -Universidade Federal de Mato Grosso, Cuiabá, 2014.

FREITAS, V. L. de O. et al. Biometria de frutos e sementes e germinação de sementes de Dimorphandra mollis Benth. e Dimorphandra wilsonii Rizz. (Fabaceae - Caesalpinioideae). Scientia Forestalis, Piracicaba, v. 37, n. 81, p. 27-35, 2009.

MARCOS FILHO, J.; CICERO, S. M.; SILVA,W. R. da. Avaliação da qualidade das sementes. Piracicaba: Fealq, 1987. 230 p.

MARCOS FILHO, J. Fisiologia de sementes de plantas cultivadas. Piracicaba: Fealq, 2005. 465 p.

MARROCOS, S. T. P. et al. Maturação de sementes de abobrinha menina brasileira. Revista Brasileira de sementes, Londrina, v. 33, n. 2, p. 272-278, 2011.

MARTINS, D. C. et al. Physiological maturity of 
eggplant seeds. Revista Brasileira de Sementes, Londrina, v. 34, n. 4, p. 534-540, 2012.

MOREIRA, G. R. et al. Espécies e variedades de pimentas. Informe Agropecuário, Belo Horizonte, v. 27 , n. 235 , p. $16-29,2006$.

NAKADA, P. G. et al. Desempenho fisiológico e bioquímico de sementes de pepino nos diferentes estádios de maturação. Revista Brasileira de Sementes, Lavras, v. 33, n. 1, p. 113-122, 2011.

NAKAGAWA, J. Testes de vigor baseados no desempenho das plântulas. In: KRZYZANOSKI, F. C.; VIEIRA, R. D.; FRANÇA NETO, J. B. (Ed.). Vigor de sementes: conceitos e testes. Londrina: ABRATES, 1999. p. 2.1-2.24

NEGREIROS, J. R. da S. et al. Influência do estádio de maturação e do armazenamento pós-colheita na germinação e desenvolvimento inicial do maracujazeiro-amarelo. Revista Brasileira de Fruticultura, Jaboticabal, v. 28, n. 1, p. 21-24, 2006.

PEREIRA, F. E. C. B. et al. Qualidade fisiológica de sementes de pimenta em função da idade e do tempo de repouso pós-colheita dos frutos. Revista Ciência Agronômica, Fortaleza, v. 45, n. 4, p. 737-744, 2014.

QUEIROZ, L. A. F. et al. Época de colheita e secagem na qualidade de sementes de pimenta Habanero Yellow. Revista Brasileira de Sementes, Brasília, v. 33, n. 3, p. 472-481, 2011.

RICCI, N. et al. Qualidade de pimenta jalapenho em função da maturação e tempo de permanência nos frutos. Pesquisa Agropecuária Tropical, Goiânia, v. 43 , n. 2, p. 123-129. 2013.

SILVA, F. A. S.; AZEVEDO, C. A. V. Assistência Estatística - ASSISTAT versão 7.7 beta. Departamento de Engenharia Agrícola do CTRN, Universidade Federal de Campina Grande - Campus de Campina Grande - PB. 2014. Disponível em: <http:// www.assistat.com/indexp.html $>$. Acesso em: $10 \mathrm{de}$ abr. 2015.

TORRES, S. B. Envelhecimento acelerado em sementes de pimenta-malagueta (Capsicum frutescens L.). Revista Ciência Agronômica, Fortaleza, v. 36, n. 1, p. 98-104, 2005.

VIDIGAL, D. de S. et al. Alterações fisiológicas e enzimáticas durante a maturação de sementes de pimenta (Capsicum annuum L.). Revista Brasileira de Sementes, Brasília, v. 31, n. 2, p. 129-136, 2009.

VIDIGAL, D. de S. et al. Changes in seed quality during fruit maturation of sweet pepper. Scientia
Agricola, Piracicaba, v. 68, n. 5, p. 535-539, 2011.

VIDIGAL, D. de S. et al. Teste de condutividade elétrica para sementes de pimenta. Revista Brasileira de Sementes, Londrina, v. 30, n. 1, p. 168-174, 2008.

WELBAUM, G. E.; BRADFORD, K. J. Water relations of seed development and germination in muskmelon (Cucumis melo L.). I. Water relations of seeds and fruit development. Plant Physiology, Wallingford, v. 86, n. 1, p. 406-411, 1988. 